\section{Leer en tiempos de COVID-19}

\author{
José María Goerlich Peset \\ Catedrático de Derecho del Trabajo \\ Universitat de València
}

ORCID ID: 0000-0002-2910-2153

https://doi.org/10.20318/labos.2020.5546

No es esta una recensión al uso. Más que diseccionar de forma crítica una concreta aportación monográfica, pretende, de un lado, presentar una visión panorámica de las que se han producido en relación con las medidas laborales y de protección social vinculadas a la particular situación creada por la COVID-19. Y, de otro, hacer alguna reflexión general sobre su impacto sobre la forma de abordar los problemas jurídicos que quizá pueda tener alguna utilidad hacia el futuro.

No he utilizado por casualidad la expresión "visión panorámica". Intento con ella ser honrado y dejar claro qué hay detrás de las reflexiones que siguen. Aunque el período de producción doctrinal que voy a considerar es relativamente breve, es posible que, en la exposición que sigue, haya preterido alguna fuente. Pido disculpas anticipadamente por ello. Asimismo, confieso que no he leído íntegramente aquellas a las que haré referencia. En muchos casos, me he limitado a pegar una ojeada. Ambas cosas tienen explicación. La suspensión de actividades ha afectado también a las bibliotecas universitarias -en el caso de la mía, sorprendentemente, la suspensión continua a pocos días de la finalización del estado de alarma-. Pero, sobre todo, la lectura completa de lo que se ha ido publicando es tarea para Sísifo -y no solo por su envergadura-.

Hechas estas precisiones, es momento de iniciar la reflexión. Por supuesto, el volumen de disposiciones emitidas en relación con la pandemia no podía no afectar a las materias laboral y de protección social. Incluso antes de la declaración del estado de alarma (RD 463/2020, de 14 de marzo), algunas de las normas de emergen- cia ya habían comenzado a afrontar problemas en estos terrenos (cfr. RRDL 6/2020, de 10 de marzo, y 7/2020, de 12 de marzo). Con posterioridad, el aluvión normativo ha sido intenso y constante. No hace falta, ni es posible, entrar en detalles. Para advertirlo, basta pegar una mirada la página inicial del BOE, encabezada ahora por los "Códigos electrónicos Covid-19": inicialmente, uno, son en la actualidad, ¡ocho! el principal de los cuales viene integrado en el momento de escribir estas líneas, el último día del estado de alarma, ¡por 231 ítems! No todo ello se refiere, claro está, a las materias que aquí interesan. Pero es obvio que están presentes, habida cuenta los específicos problemas que se han suscitado en el ámbito de las relaciones laborales y las obvias repercusiones de la parálisis económica sobre el mercado de trabajo y las rentas a disposición de personas y familias.

Como era previsible, la aparición de estas nuevas normas ha propiciado también la de una serie de análisis en relación con su alcance. Es lo normal en los casos en los que se producen reformas normativas, que se abordan bien en una perspectiva de conjunto bien parando la atención en alguna o alguna de las instituciones afectadas por los cambios. $Y$ así ha ocurrido también en relación con el ciclo normativo vinculado a la COVID-19.

Entre los análisis de amplio espectro, cabe traer a colación, en el ámbito de la editorial Tirant lo Blanch tres comentarios a las reformas: Análisis normativo de las medidas laborales y de Seguridad Social frente a la crisis del COVID-19, cuyos autores son A. Blasco Pellicer, M. López Balaguer, M. Alegre Nueno, F. Ramos Moragues y E. Taléns Visconti, COVID-19: Medidas del RDL 8/2020 en el ámbito laboral. Doctrina, legislación y formularios. Preguntas y respuestas, de C. Alfonso Mellado y G. Fabregat Monfort, y la Guía práctica de las medidas laborales extraordinarias adoptadas frente a la crisis sanitaria del COVID-19, de T. Sala Franco y M. Velasco Paños. Por su parte, Francis Lefebvre ha publicado una "guía rápida" titulada Impacto del COVID-19 en materia laboral y de seguridad social, coordinada por C. Aragón Gómez (coord.) en la que hemos participado un amplio grupo de profesores de varias Universidades. Finalmente, 
ha de traerse a colación el número 4 (2020) de la revista Derecho de las relaciones laborales, que contiene un extenso monográfico sobre El Derecho del Trabajo y de la Seguridad Social ante la Pandemia de COVID-19, al que han contribuido importantes laboralistas.

Junto a estas aportaciones más generales, se ha publicado alguna monografía sobre las principales instituciones afectadas. Valga, como ejemplo, el estudio de R. Roqueta Buj sobre Los expedientes de regulación temporal de empleo, editado también por Tirant, que, según reza en la portada, "incluye las medidas excepcionales en relación a los ERTEs por causas relacionadas con el COVID-19".

En cuanto a las revistas, aparte el monográfico reseñado, encontramos aproximaciones generales a las nuevas normas. A veces se trata de trabajos más descriptivos, en la misma línea que las monografías reseñadas, aunque necesariamente más breves. Cabe traer a colación aquí los artículos de J. Cordero González, en Trabajo y Derecho 65 [2020], J.A. Fernández Avilés Revista de Trabajo y Seguridad Social. CEF 445 [2020] o M.T. Agut García en esta misma revista 447 [2020]. Otras veces, tienen un mayor componente crítico en relación con las opciones formales y de política legislativa adoptadas. Cabría señalar, en este terreno, un segundo estudio de J. Cordero, en Trabajo y Derecho 66 [2020] y las dos editoriales de C. Molina en la Revista de Trabajo y Seguridad Social. CEF 446 [2020] y 446 [2020]. Por lo demás, encontramos estudios sobre los diferentes aspectos afectados por las normas COVID. Los hay en materia de seguridad social, bien realizando un análisis general (A.R. Trillo García en Trabajo y Derecho 66 [2020], o E. Taléns en Revista de Trabajo y Seguridad Social. CEF 445 [2020]) bien volcándose en las reglas en materia de cotización (J. Mercader, en Trabajo y Derecho 66 [2020]); pero también en materia preventiva (J. Cordero González en Trabajo y Derecho 65 [2020]), procesal (J. Ercilla en Revista de Trabajo y Seguridad Social. CEF 446 [2020]) o en relación con el propio ejercicio del derecho de huelga (Ituren y Esteve, en Trabajo y Derecho 65[2020]).

En muchos casos, estos estudios miran a solucionar los problemas prácticos derivados de las nuevas normas introducidas para hacer frente a la pandemia. Como hemos visto se presentan como "guías" o incluyen "preguntas y respuestas". Se trata de una tarea siempre necesaria en caso de reforma normativa y que lo ha sido particularmente en el período que analizamos. Las nuevas normas se refieren a instituciones que no siempre se han encontrado en el centro del debate teórico ni, sobre todo, en el de la aplicación práctica del ordenamiento laboral: son buenos ejemplos de ello dos de las instituciones a las que se ha asignado un papel decisivo, la regulación temporal de empleo por fuerza mayor y el teletrabajo. Por otro lado, se han abierto paso soluciones excepcionales, cuyo anclaje con las reglas generales preexistentes resulta complejo. Finalmente, la producción normativa se aleja de los patrones tradicionales: aparte de la pérdida del sentido de la forma como garantía, hemos asistido a un verdadero torrente normativo, que incluye rápidas correcciones o matizaciones de las soluciones que introducidas días antes. Quizá ocasionalmente ello se deba a que se han adoptado decisiones con cierta improvisación; pero en la mayor parte de las ocasiones las normas han ido a remolque de la evolución de la pandemia y de la percepción de los problemas. Un sólido esfuerzo doctrinal de racionalización de este material normativo resulta, pues, absolutamente necesario.

Creo, sin embargo, que la pandemia y sus consecuencias constituyen una singularidad, en la que los instrumentos tradicionales muestran claras limitaciones. Las propias características del torrente normativo que nos ha inundado dificultan que las aportaciones doctrinales, al menos en su formato clásico, cumplan la función que les corresponde. Para demostración de esta idea puedo poner como ejemplo mi propia experiencia. En la ya citada "guía rápida” coordinada por C. Aragón, se me asignó el capítulo dedicado "Obligaciones retributivas y de Seguridad Social en la crisis sanitaria". Por lo que se refiere a las segundas, en el momento de entregar el capítulo, había entrado en vigor el RDL 11/2020, de 31 de marzo, previendo una moratoria (art. 34) y un régimen especial de aplazamiento (art. 35). En pruebas fue posible tener en cuenta la modificación introducida en la primera por RDL 13/2020; la modifica- 
ción del segundo por RDL 15/2020, de 21 de abril, ya no pudo ser tomada en consideración. Como tampoco pudo serlo la inmediata Orden ISM/371/2020, de 24 de abril, que concretaba las reglas del art. $34 \mathrm{RDL} 11 / 2020$. Trayectorias similares, por lo demás, se detectan en otras instituciones: las diferentes reglas especiales en materia de regulación temporal de empleo establecidas en RDL 8/2020, de 17 de marzo, han sido afectadas en diferentes facetas por RRDDLL 9/2020, de 27 de marzo, y 16/2020, de 28 de abril, 18/2020, de 12 de mayo y modificadas por RDL 15/2020, de 21 de abril.

No es de extrañar, en este contexto, que varias de las obras generales que se han enumerado más arriba hayan tenido ya una segunda edición. Pero sí que es llamativo que hayan dejado de tener existencia física. De forma inmediata solo puede accederse a las mismas a través de su versión electrónica; la edición en papel está "sólo disponible en IBD (impresión bajo demanda)". La forma tradicional de divulgación del conocimiento especializado parece superada por las exigencias derivadas de la pandemia. $\mathrm{Y}$, a cambio, se ha incrementado la presencia de otros instrumentos relacionados con los avances tecnológicos. Han proliferado los webinars o similares, han aparecido círculos y grupos en las redes sociales vinculados a la resolución de las dudas que se han venido suscitando en el período y, por lo que aquí interesa, los blogs existentes en el área se han dedicado de forma prácticamente exclusiva a la problemática COVID-19. E. Rojo, en El nuevo y cambiante mundo del trabajo. Una mirada abierta y crítica a las nuevas realidades laborales, ha entreverado con otras aportaciones, reiteradas actualizaciones "de normativa, resoluciones judiciales, y aportaciones económicas, jurídicas y sociales", con sorprendente frecuencia. Por su parte, en su Una mirada crítica a las relaciones laborales, I. Beltrán de Heredia nos ha ofrecido hasta la fecha más de 30 entradas sobre el tema que nos ocupa, y el Foro de Labos, ha superado las cuarenta. Otros blogs, sin alcanzar esta intensidad, incluyen también aportaciones sobre diferentes aspectos.

Esta forma emergente de reflexionar sobre el derecho es, desde luego, particularmente útil en circunstancias como las que hemos vivido. Permite afrontar los problemas de forma prácticamente simultánea a su aparición. Pero hay que ser conscientes también de sus posibles limitaciones. Brevedad e inmediatez de la respuesta, aparte sus posibles riesgos en términos de profundidad, abren un modelo de reflexión muy apegado a las circunstancias del día. Ello implica que se desarrolle de forma un tanto asistemática y muy apegada a lo cotidiano.

Sin embargo, y con ello termino, la COVID-19 requiere una reflexión mucho más amplia, que trascienda los problemas concretos suscitados por el aluvión normativo que se ha aprontado para afrontarla. El fuerte impacto que estas han tenido sobre el sistema económico y social hacen que no sea solo importante predecir las respuestas judiciales o administrativas en la aplicación de las nuevas normas. Dado que no tenemos claro que las cosas vuelvan a ser como eran antes de la irrupción de la pandemia, implica que sea también importante, y quizá más, contribuir a la nueva configuración de las instituciones laborales. Entre los trabajos a los que se hace referencia en esta reseña se encuentran relevantes aportaciones. Pero espero que veamos más en el futuro inmediato. 